\title{
A brief introduction to the history of community informatics
}

\author{
Peter Day
}

Published online: 1 July 2010

(C) Springer-Verlag London Limited 2010

Any introduction to community informatics requires an understanding of the historical development of the field. I first encountered the term 'community informatics' as a member of a panel at the 20th ICIS conference in Charlotte, North Carolina in 1999 (Gurstein et al. 1999), although it is not entirely clear when or where the term was first used (see e.g. Gurstein 2000; Keeble and Loader 2001), or who first used it. What is clear is that they were not inventing a new field of practice. The appropriation and utilisation of a broad range of information and communication technologies by community development workers, community groups, clubs, associations, etc., in the community interests-e.g. community networks, community information networks, community telecottages/telecentres and community media-existed long before community informatics emerged as an academic construct. As a community activist I was using communication technologies, albeit more primitive than those available today, to produce community newsletters during the 1980s. Similarly, as an academic researcher, I have been engaged with community communication and information initiatives and associated research since 1993 and I was most certainly not the first.

In its early days, the push behind community informatics represented little more than an attempt to pull together a number of globally dispersed researchers who occasionally met one another on the conference circuit. This small but growing throng of academics identified a desire to create a platform for critical commentary on the growing impacts of technological convergence at the community level. Our intention was to mirror and forge

P. Day $(\bowtie)$

School of Arts \& Media, Faculty of Arts, University of Brighton,

Watts Building, Brighton BN1 4GJ, UK

e-mail: P.Day@bton.ac.uk links with the Global Community Network Partnership (GCNP)—ostensibly an international partnership of community network practitioners. The rationale was to establish common ground and dialogue between community technology practitioners and researchers. However, GCNP folded around the time that The Community Informatics Research Network (CIRN) was established at the University of Monash Centre in Prato, Italy in 2003. This left us with an enthusiastic but emergent network of interested academics but few community practitioners. This is not to suggest that CIRN participants do not have associations with community practitioners. Quite the reverse is true, some have amazing networks and partnerships across a diverse range of community practice and policy makers as well as social movement groups and ICT practitioners, designers and academics. However, many practitioner colleagues simply cannot afford to attend international conferences, and since the inaugural CIRN conference in 2004, an annual conference has been held in Prato, ${ }^{1}$ attended mainly by academics.

Since those early developments, one of the most noticeable things about CIRN has been its lack of any organisational structure. Annual conferences have been held in Prato since the 2003 launch, with another in Brighton and one in Cape Town. There is an online journal, ${ }^{2}$ edited by Michael Gurstein, a founder member of CIRN, with an editorial board of CIRN supporters and yet CIRN only exists as a loose but determined network of academic community researchers/practitioners. There is no official membership, no form of internal governance and no formal way of determining who or what CIRN is and what it represents. Additionally, there are no decision making

\footnotetext{
${ }^{1}$ See http://www.ciresearch.net/ for further information.

${ }^{2}$ http://www.ci-journal.net/index.php/ciej.
} 
processes, which means that sometimes there is a lack of clarity about who should be accountable to whom and about what. Everything that has been achieved has been done through the goodwill, hard work and dedication of a small hub of people who interact with a much larger number of 'members'.

\section{Community informatics-understanding its complexity}

The preceding section only hints at an explanation for the lack of clarity surrounding CIRN. As a field of activity or subject of study, the waters surrounding the nascent discipline of community informatics are muddied still further by the fact that community informatics represents two distinct but related areas of social interaction and endeavour: (1) the study of community uses of ICT, i.e. community informatics as a field of research; and (2) the practices of community ICT usage, i.e. community informatics as a field of practice. Community informatics therefore comprises 2 main component parts_-research and practice. These component parts can in turn be sub-divided still further into areas of activity and discourse coming from often diverse and divergent cultures. Informatics practice, for example, is influenced by information systems design, computer programming, web development, Web 2.0 and social networking sites, digital media, content management systems and so on. However, because the context for these informatics activities is community they can and should be-but are not always-influenced by community development workers/agencies, community organisers, community groups and even community policy makers. There is a need for dialogue between these and many other fields of human endeavour. If we then factor in the different academic disciplines and milieu of diverse academic and organisational cultures of those interested in community informatics research, a rich picture of complex believes, norms, value systems and practices begins to emerge. It is for these reasons of cultural complexity and diversity that I approached AI \& Society to run a series of community informatics special editions. The humancentred tradition is no stranger to such complexity and it is my firm belief that there is a mutual benefit to be gained in sharing our experiences and knowledge in the best traditions of both human-centred design and community informatics.

\section{Technology as a social structure}

It is widely understood that social structures such as law, politics, religious and cultural beliefs, the economy and even language shape social interaction and that social experience and interaction shape social structures in turn. Despite this understanding, a deep-rooted and passive acceptance of technology exists at many levels of the information society or digital age. It is almost as if a myth surrounds technology (Illich 1990). As a society, we appear more inclined to accept social circumstances resulting from the implementation and use of ICT than we are for other, more familiar, social structures (Sclove 1995). Because ICT have been portrayed as modern, inevitable and, of course, fun-linked as they are to the consumption of entertainment goods and services-they are often not subject to the same public scrutiny that other social structures receive, despite their pervasive nature. As such, ICT often remain the undemocratic preserve of 'experts'.

A consequence of this has been that the development of information society or digital age social policy, depending, as it does, almost exclusively on the advice of 'experts' involved in the production of entertainment goods and services, often fails to meet the broader social needs, ideals and aspirations of culturally diverse citizens and communities in a democratic society.

Of course, interpretation of democracy is subjective and can take many forms (Giddens 1993). However, here we adopt Galbraith's belief that participation is a central component for both democracy and a sense of community that not only values but also celebrates diversity in society (1994), which we believe forms a basic tenet of a human-centred philosophy. Applying this understanding of democracy in the 'digital age' or 'information society' leads naturally to an argument that,

If citizens ought to be empowered to participate in determining their society's basic structure, and technologies are an important species of social structure, it follows that technological design and practice should be democratized.

(Sclove 1995, pp 26-27)

From a community informatics perspective, as citizens participate in the design, implementation and development processes of community ICT initiatives, changes can result in the technological order which exert structural influence on the democratic process. Through this participation the democratic process, in turn, affects the community technological order. However, arguments relating to participative democracy in an 'information society' remain abstract unless they are expanded into a framework of specific guidelines for democratic design, or democratic design criteria (Slove 1995). It is beyond the scope of this special edition to develop such a framework here. Some of our contributing authors hint at one but, for now, the important point is to understand that such criteria should 
not be reified; that they can and should be adapted to suit circumstance, need and changes therein.

Within local communities such design criteria should always represent the citizens' best assessment of collective and individual aspirations and needs. There can never be a blueprint or 'one best way' (Taylor 1911) of designing democratic technologies, which underlines the importance of valorising diversity.

\section{Pathways of knowledge}

Whilst not developing a framework or a set of guidelines for democratic design criteria here, this special issue consists of eight papers intended to provide a flavour of some of the pioneer contributions to emerge from the field of community informatics over the past decade. These papers are not intended to be prescriptive in any way. They are not necessarily the only way community informatics could be represented to a new audience. The purpose of this special edition is to provide some historical insights, by way of introduction, into the practices and experiences of the early community informatics pioneers. Over the next few years, a number of community informatics special editions will present more detailed coverage of specific areas of theory and practice likely to be of mutual interest to colleagues from both human-centred and community technology traditions. The knowledge and experiences presented here are intended to promote critical reflection and stimulate dialogue between, practitioners (community and ICT), community-based and academic researchers/theorists, and policy-makers interested in building active and healthy community in the digital age and in contributing to the empowerment of community voice through the tools, spaces and processes of human-centred community informatics.

De Cindio and Ripamonti's paper provides a critical exploration of the nature and roles of community networks in the information society through the lenses of multidisciplinary, action research and participatory approaches developed by the Community Informatics Laboratory at the University of Milan. The Milan Community Network (RCM, Rete Civica di Milano) was 'born' in September 1994, and its original aim was to facilitate or enable citizen engagement in shaping what was then known in policy and academic circles as the Information Society (see e.g. Commission of the European Communities 1994; Gore 1993; Webster 1995). Identifying and reflecting critically on a range of ways in which 'Internet-based communities' were perceived at the time, the authors propose a framework of four dimensions that characterise 'online communities'. This framework is then employed in their analysis of the roles community networks 'can and should play in the Information Society' and subsequent discussion of the sustainability of community networks. As a counter to claims often heard that physical community space is no longer relevant in an age of individualised networks, the authors conclude that "citizen participation in shaping the Information Society has to be rooted where people live and work' and present a new mission, and vision, for RCM.

De Moor's contribution to this special edition examines how civil society might be reconstructed through Intermedia community systems such as a group authoring report support system (GRASS) tailored to meet the needs and constraints of the 'communities grown around them'. Introducing the concept of 'wicked problems' within a context of globalisation and (un)sustainable development, de Moor argues that the world urgently needs a rejuvenated civil society-the main source of communitarian virtues as a check against the power of the state and the inequalities of the marketplace. Identifying an intermediary role for civil society for societal conflict resolution, the author notes that all too often only a 'tiny proxy of civil society is involved in key stakeholder debates', with a resultant exclusion of 'many voices.' Raising the potential scope of communities of co-operation, the paper focuses on the role of 'interpersonal, cross-organisational communities of diverse stakeholders' as well as 'how to grow these emergent communities around Internet technologies.' Introducing the notion of Intermedia as Internet technologies used to facilitate societal discourse, four important functions of Intermedia discourse are identified-participation, feedback, monitoring and trust building. These are used in a reflective discussion of the design principles, functionality and implementation experiences of GRASS. The knowledge garnered from these experiences is then fed back into an extensive concluding examination of building online communities using Intermedia.

In a thought provoking and challenging paper, Schuler synthesizes the main themes identified in the previous two contributions in a significant work that highlights the symbiotic nature of the relationship between practice and theory in community informatics, especially when viewed through human-centred lenses. In a paper designed to explore the relationship between community networks and civic intelligence, Schuler describes the latter as a nascent concept that 'describes the capacity of society to consciously adapt to its environment and shape a future environment that is healthy, equitable and sustainable.' Presenting community networks as an important manifestation of civic intelligence during the early years of the Internet, the paper provides a US orientation of community networks and networking, to complement the Euro-centric focus of the previous papers. Arguing that by strengthening the core values of community - conviviality and culture, education, strong democracy, health and well being, 
economic equity, opportunity and sustainability, and information and communication-it is possible to build stronger, more coherent communities, Schuler draws out the relationship between theories and practices of social capital and community networking before introducing his emergent theory of civic intelligence. In an echo of the 'human purpose' (Rosenbrock 1990) and Cooley's 'architect or bee' (Cooley 1987) theses, Schuler describes civic intelligence as creative, active, non-deterministic and human-centred by placing people rather than abstract systems or 'very general historic forces' at the core of social change. Having explored community networks as manifestations of civic intelligence and presented detailed descriptive and functional models of civic intelligence that provide a critical analyses of the nascent theory, the paper completes the conceptual circle by reflecting critically on the contribution that civic intelligence may now make to community networking in the future.

In contrast to mutually beneficial relationship between theory and practice outlined in the previous offerings, the next few contributions illustrate the symbiotic relationship that exists between community informatics research and practice.

In a study entitled 'Technologies of care in community based organizations', Stillman focuses on issues of agency and authenticity by employing structuration theory to analyse the data from 23 in-depth, semi-structured interviews with workers about the value of using ICT in Neighbourhood Houses-which fulfil 'three core tasks of community development: self-help, the realisation of feltneeds, and increased participation in family and community life'. Stillman's project starts from the premise that if ICT are to be used effectively for social justice purposes at the community level, 'then community-based organizations (CBOs) are critical partners in such activity.' Having provided an effective analysis of his research findings, Stillman provides a methodological update from a more recent but related project. 'Doing IT better' is a collaborative action research project which partnered a number of CBOs in exploring how representational software might be used to offer new opportunities of benefit to CBOs by 'capturing' tacit knowledge for collaborative uses.

Williamson's paper also makes a methodological contribution to our understanding of community informatics but his research is conducted in a policy context-eDemocracy. One of the significances of this paper, and that of Taylor, et al., later on, is that it allows us to highlight the relational links between practice, research, theory and policy that underpins all community informatics activities. Discussion of these relationships will form the basis of a future community informatics special edition.

Williamson's research explores 'factors affecting the uptake of electronic democracy processes... from a citizen- driven (bottom-up) perspective and highlights the need for building capacities and capabilities before ICT can be used as effective community tools'. Williamson provides some fascinating insights into the history of, and governance processes in, New Zealand. All of which is juxtaposed to a reflective discussion of a grounded and mixed methods research methodology that enabled a rich and enhanced understanding of: (1) citizen perceptions of eDemocracy, and (2) how ICT might be used to re-engage and empower citizens, to emerge.

Foth adopts an innovative approach to practice-based community informatics research. His approach recognises the significance of network qualities in the communicative ecologies that constitute urban community. Using what he terms a tripartite approach to his research-participation, animation and design-Foth describes the 5 stages of his research methodology that includes the design of a community network system that not only links with Internet and Web 2.0 communication services for individualised networking but also possesses collective communication features that 'supplement the communicative ecology of urban residents and provides voluntary and tiered access to proximate communication and interaction.' Furthermore, Foth stresses that the system be designed in such a way so as to facilitate local ownership; engagement in decision making; responsibility sharing and be driven by the residents themselves.

Gaved and Mulholland analyse the success of community technology initiatives globally in addressing the digital divide through community connectivity. They highlight a range of problems arising from a number of externally funded, socio-technical, community experiments, and propose that bottom-up, grassroots approaches; initiated, owned and driven from within a community have greater scope and more potential for sustainability in the community than external interventions. The authors present the results of a survey of grassroots networked community initiatives and identify key characteristics and modes of operation of such initiatives in the United Kingdom by developing a typology of co-operatives, sub-cultures and pioneers. The characteristics and modes of operation are discussed within the context of a participatory action research project planned for the near future.

Set against the backcloth of the emerging discourses of i-society and e-government, Taylor et al. discuss the paradoxical nature of the impact of ICT within a context of the social appropriation of e-government. The authors highlight the implications for decision making and power relationships in governance and propose an urgent need for government agency to value meaningful partnerships with civil society in the development of information society policy. 


\section{References}

Commission of The European Communities (1994) Europe and the global 'information society': recommendations to the European Council. [The Bangemann Report] CD-84-94-290-EN. http://ec. europa.eu/archives/ISPO/infosoc/backg/bangeman.html

Cooley M (1987) Architect or bee? The human price of technology. Hogarth Press, London

Galbraith JK (1994) The Good society considered: the economic dimension. J Law Soc. [Annual Lecture-St. David's Hall, Cardiff. 26/1/94] Cardiff: Cardiff Law School

Giddens A (1993) Sociology, 2nd edn. Polity Press, Oxford

Gore A (1993) Speech to the press club. http://www.ibiblio.org/nii/ goremarks.html

Gurstein M (2000) Community informatics: enabling community uses of information and communications technology. In: Gurstein M (ed) Community informatics: enabling communities with information and communication technologies. Idea Group, Hershey, pp 1-31
Gurstein M et al (1999) In: Proceedings of the twentieth international conference on information systems, Dec 13-15, 1999 Charlotte, North Carolina, USA. Association for Information Systems, Atlanta, GA, USA, http://portal.acm.org/citation.cfm?doid= 352925.353009

Illich I (1990) Tools for conviviality. Marion Boyars, London

Keeble L, Loader B (2001) Community informatics: shaping computer-mediated social relations. Routledge, London

Rosenbrock H (1990) Machines with a purpose. Oxford University Press, Oxford

Sclove RE (1995) Democracy and technology. Guilford Press, London

Taylor FW (1911) Principles of scientific management. Harper \& Row, New York

Webster F (1995) Theories of the 'information society'. Routledge, London 